\title{
Frontières
}

\section{Quelques réflexions de... Peter F. Trent}

\section{Peter F. Trent}

Volume 12, numéro 1, automne 1999

Suicides, générations et culture

URI : https://id.erudit.org/iderudit/1075918ar

DOI : https://doi.org/10.7202/1075918ar

Aller au sommaire du numéro

Éditeur(s)

Université du Québec à Montréal

ISSN

1180-3479 (imprimé)

1916-0976 (numérique)

Découvrir la revue

Citer ce document

Trent, P. F. (1999). Quelques réflexions de... Peter F. Trent. Frontières, 12(1),

52-52. https://doi.org/10.7202/1075918ar d'utilisation que vous pouvez consulter en ligne.

https://apropos.erudit.org/fr/usagers/politique-dutilisation/ 


\section{Quelques réflexions de... Peter F. Trent \\ maire de la Ville de Westmount}

Pourquoi est-ce que de plus en plus d'hommes québécois se donnent la mort? Avant d'explorer les courants sociétaux profonds et troubles qui peuvent avoir conduit à ce malheureux état de fait, nous pouvons supposer qu'ailleurs dans le monde, là où l'on considère fréquemment le suicide comme un acte lâche et honteux, bon nombre de cas ne sont pas déclarés. Dans ces sociétés, on peut faire passer les suicides pour d'autres types de mort. Pour d'autres sociétés moins portées au jugement (comme celle du Québec), cette forme de sortie définitive peut être plus acceptable. En effet, la laïcisation qu'a connue le Québec au cours des trois dernières décennies a dissipé l'opprobre religieux, alors qu'autrefois, comme disait Shakespeare, «l'Éternel avait fixé un canon contre le meurtre de soi».

Cela mis à part, pourquoi le taux de suicides est-il plus faible chez nos voisins du Sud? L'on s'attendrait pourtant à ce qu'au "pays de la liberté» cet acte d'individualisme extrême soit encore mieux admis qu'ici. Car les États-Unis sont bien le pays du Marlboro Man, ce solitaire qui règle les problèmes de sa main; contrairement à Hamlet, ce Danois hésitant que son intellect réduit à l'inaction. Ne sont-ils pas aussi le pays dont l'industrie du divertissement banalise la mort d'autrui et fait l'éloge de la violence? Pourquoi pas alors de la violence intériorisée? Ah! mais c'est que les Américains, outre qu'ils soient plus religieux que nous, ne peuvent admettre l'échec. Ainsi, un acte de profanation tel que le suicide leur parait impardonnable.

Si le suicide est un moyen de communication désespéré - une manière de crier son désespoir face à la dureté de la vie -, alors il est vain. Si, par contre, il résulte d'une décision réfléchie, mûrie, alors il doit être respecté. La personne qui souffre peut juger l'amputation de son être préférable à l'agonie qu'inflige le traitement de l'insoignable. C'est la seule façon dont le survivant que je suis arrive à rationaliser ce geste. 